\title{
BMJ Open Comparison of the airway complications of subtypes of laryngeal mask airway and i-gel in child patients under general anaesthesia: a protocol for systematic review and network meta-analysis of randomised control trials
}

\author{
Jieting Liu, ${ }^{1,2,3}$ Xiaonan Xu, ${ }^{4}$ Muyang Li, ${ }^{5}$ Runjin Cai, ${ }^{5}$ Kehu Yang ${ }^{1,3,6}$
}

To cite: Liu J, Xu X, Li M, et al. Comparison of the airway complications of subtypes of laryngeal mask airway and i-gel in child patients under general anaesthesia: a protocol for systematic review and network meta-analysis of randomised control trials. BMJ Open 2020;10:e032691. doi:10.1136/ bmjopen-2019-032691

- Prepublication history and additional material for this paper are available online. To view these files, please visit the journal online (http://dx.doi org/10.1136/bmjopen-2019032691).

Received 01 July 2019 Revised 29 November 2019 Accepted 17 December 2019
Check for updates

(C) Author(s) (or their employer(s)) 2020. Re-use permitted under CC BY-NC. No commercial re-use. See rights and permissions. Published by BMJ.

For numbered affiliations see end of article.

Correspondence to

Professor Kehu Yang;

kehuyangebm2006@126.com

\section{ABSTRACT}

Introduction Laryngeal mask airway (LMA), an alternative to traditional tracheal intubation, is widely used in clinical practice and is considered to be an effective device for airway management. LMA and i-gel have been widely used in anaesthesia and emergency situations in children. Some systematic reviews have evaluated the efficacy of LMA and i-gel in children, but they have not shown consistent results in clinical performance. This study aims to evaluate the airway complications of all subtypes of LMA and i-gel in child patients under general anaesthesia using a Bayesian network meta-analysis (NMA).

Methods and analysis PubMed, EMBASE.com, the Cochrane library, Web of Science and Chinese Biomedical Literature Database will be searched from inception to January 2019. We will include prospective randomised controlled trials (RCTs) that reported the subtypes of LMA and i-gel regardless of sample size. The risk of bias assessment of the included RCTs will be conducted according to the Cochrane Handbook V.5.1.0. A Bayesian NMA will be performed using WinBUGS V.1.4.3. Grading of Recommendations Assessment, Development and Evaluation will be used to explore the quality of evidence. Ethics and dissemination Ethics approval and patient consent are not required as this study is an NMA based on published trials. The results of this NMA will be submitted to a peer-reviewed journal for publication. PROSPERO registration number CRD42019127668.

\section{INTRODUCTION}

In 1983, Brainhas introduced the new concept in airway management-laryngeal mask, but the laryngeal mask airway (LMA) was introduced in 1988 in the USA. ${ }^{12}$ The LMA gained a wide application in clinical practice as an alternative to traditional tracheal tube intubation and is considered as an effective device for airway management if face mask ventilation and intubation failed or are expected to be unfeasible due to airway malformations or to the specific work setting. ${ }^{3-5}$ At the same
Strengths and limitations of this study

- This study will be the first network meta-analysis comparing the airway complications of subtypes of laryngeal mask airway and i-gel in child patients under general anaesthesia.

- Two reviewers will independently conduct the study selection, data extraction and quality assessment.

- The quality of evidence will be assessed by the Grading of Recommendations Assessment, Development and Evaluation system.

- Both pairwise meta-analysis and network metaanalysis will be performed.

Our results will be limited by the number of available trials and the quality of included trials.

time, LMA has been demonstrated to be easily placed by medic and paramedic staff. ${ }^{6}$

A variety of LMAs has been introduced in the field of anaesthesia and emergency situations in child patients. Compared with most LMAs with an inflatable cuff, on the contrary, i-gel is one of the second generation and a relatively newer addition to the armamentarium of supraglottic airways. I-gel is different from all other laryngeal masks in that it does not have an inflatable cuff, rather, i-gel has a soft gel-like cuff that is made of medicalgrade transparent thermoplastic elastomer that does not require inflation. ${ }^{78}$ Previous systematic reviews (SRs) or meta-analyses in the field of anaesthesia did not show consistent results in the clinical performance. ${ }^{910} \mathrm{At}$ the same time, significant risk factors for postoperative airway complications related to the use of different subtypes of LMA or i-gel in child patients, which are not assessed by the network meta-analysis (NMA). 
NMA has been considered to extend conventional meta-analysis on multiple treatments for a given condition. ${ }^{11}{ }^{12}$ As we know, well-conducted SRs and metaanalyses of randomised controlled trials (RCTs) are often considered the best way to obtain evidence of healthcare decisions. ${ }^{13-16}$ Compared with pairwise meta-analyses, NMAs allow for visualisation of a larger amount of evidence, estimation of the relative effectiveness among all interventions (even if some head to head comparisons are lacking) and rank ordering of the interventions. ${ }^{17}$ The value of NMAs for healthcare decision making has been recognised and accepted by different health technology assessments and funding agencies worldwide. ${ }^{18}$ Therefore, we will conduct an SR and NMA to evaluate the airway complications of all subtypes of LMA and i-gel in child patients under general anaesthesia.

\section{METHODS}

The current NMA will be conducted by following the Preferred Reporting Items for Systematic Reviews and Meta-Analyses guidelines. ${ }^{19}$

\section{Eligibility criteria}

Type of study

We will include prospective RCTs that reported the subtypes of LMA and i-gel regardless of the sample size.

Type of patients

Child patients are younger than 18 years of age under general anaesthesia.

\section{Type of interventions}

All subtypes of LMAs will be included: Classic LMA, Fastrach LMA, Proseal LMA, Unique LMA, Flexible Reinforced LMA and Supreme LMA.

\section{Type of outcomes}

The primary outcome will be the incidence of airway complications, which will be related to the choice of device size of cuff, including sore throat, dysphagia, dysphonia, cough, blood on device, lip trauma and laryngospasm. The second outcome will include specific types of airway complications if data are available.

\section{Data sources}

PubMed, EMBASE.com, the Cochrane Library, Web of Science and Chinese Biomedical Literature Database will be searched from inception to 31 January 2019. At the same time, the reference lists of published reviews and retrieved articles will be checked for additional trials.

\section{Study selection}

Two review authors will independently screen titles and abstracts of each record retrieved by EndNote X8 (Thomson Reuters (Scientific) Philadelphia, Pennsylvania, USA). Then, full texts of all potentially relevant studies will be obtained and reviewed for further assessment. Disagreements will be discussed or by a

\begin{tabular}{|c|c|}
\hline Item & Content \\
\hline Publication details & $\begin{array}{l}\text { Name of author } \\
\text { Year of publication } \\
\text { Name and impact factor of journal }\end{array}$ \\
\hline Participant details & $\begin{array}{l}\text { American Society of Anesthesiologist } \\
\text { Classification } \\
\text { Sex } \\
\text { Age } \\
\text { No of participants } \\
\text { Setting }\end{array}$ \\
\hline Device details & $\begin{array}{l}\text { Type of device } \\
\text { Methods of selection device size }\end{array}$ \\
\hline Surgery details & $\begin{array}{l}\text { Time of surgery } \\
\text { Type of surgery }\end{array}$ \\
\hline $\begin{array}{l}\text { Airway } \\
\text { complications }\end{array}$ & $\begin{array}{l}\text { Method of registration of airway } \\
\text { complications } \\
\text { Time of airway complications } \\
\text { Sore throat } \\
\text { Dysphagia } \\
\text { Dysphonia } \\
\text { Cough } \\
\text { Blood on device } \\
\text { Laryngospasm } \\
\text { Other }\end{array}$ \\
\hline Risk of bias & $\begin{array}{l}\text { Random sequence generation } \\
\text { Allocation concealment } \\
\text { Blinding of participants and personnel } \\
\text { Blinding of outcome assessment } \\
\text { Incomplete data } \\
\text { Selective outcome reporting } \\
\text { Other bias }\end{array}$ \\
\hline
\end{tabular}

third reviewer if no consensus is reached. We will use a predefined extraction form with detailed written instructions which will be created using Microsoft Excel 2013 (Microsoft, Redmond, Washington, USA, www.microsoft. com) to collect relevant information and data. ${ }^{20}$ Data will be extracted from eligible studies including publication details, participant details, device details, surgery details, airway complications and risk of bias. Any missing data will be acquired by contacting the author by email (table 1 ).

\section{Search strategy}

The key search terms are laryngeal mask, laryngeal mask airway, LMA, i-gel, and their synonyms. Full details of the search strategies can be found in online supplementary appendix 1. Search strategy of PubMed as follows: 
\#1 "Laryngeal Masks"[Mesh] OR laryngeal mask airway*[Title/Abstract] OR laryngeal mask*[Title/ Abstract] OR aryngeal mask*[Title/Abstract] OR arynx mask*[Title/Abstract] OR LMA[Title/Abstract]

\#2 i-gel[Title/Abstract] OR igel[Title/Abstract] OR i gel[Title/Abstract]

\#3 \#1 OR \#2

\#4 "Clinical Trials, Phase II as Topic" [Mesh] OR "Clinical Trials, Phase III as Topic"[Mesh] OR "Clinical Trials, Phase IV as Topic"[Mesh] OR "Controlled Clinical Trials as Topic"[Mesh] OR "Randomized Controlled Trials as Topic"[Mesh] OR "Intention to Treat Analysis"[Mesh] OR "Pragmatic Clinical Trials as Topic"[Mesh] OR "Clinical Trials, Phase II"[Publication Type] OR "Clinical Trials, Phase III"[Publication Type] OR "Clinical Trials, Phase IV"[Publication Type] OR "Controlled Clinical Trials" [Publication Type] OR "Randomized Controlled Trials"[Publication Type] OR "Pragmatic Clinical Trials as Topic"[Publication Type] OR "Single-Blind Method"[Mesh] OR "Double-Blind Method"[Mesh]

\#5 random*[Title/Abstract] OR blind*[Title/ Abstract] OR singleblind*[Title/Abstract] OR doubleblind*[Title/Abstract] OR trebleblind*[Title/ Abstract] OR tripleblind*[Title/Abstract] \#6 \#4 OR \#5

\#7 \#3 AND \#6

\section{Risk of bias of individual studies}

Two reviewers will independently use the Cochrane Handbook V.5.1.0 for SRs of intervention to assess the quality of included RCTs. ${ }^{21}$ We will resolve any disagreement by discussion or by involving a third review author. The Handbook includes random sequence generation, allocation concealment, blinding of participants and personnel, blinding of outcome assessment, incomplete outcome data, selective reporting and other sources of bias. We will rate the methodological quality as low, high or unclear risk of bias. Bias in RCTs will be evaluated for seven items: method of random sequence generation (selection bias), allocation concealment (selection bias), participant and personnel blinding (performance bias), outcome assessment blinding (detection bias), incomplete data (detection bias), selective reporting (detection bias) and other bias. Each item will be classified as high, low or unclear risk of bias.

\section{Geometry of the evidence network}

A network plot will be created to describe and present the geometry of the intervention network of comparisons across trials using STATA (V.13.0; Stata). If a pair of interventions are not connected to the rest of the network, we will exclude those interventions from the NMA and describe that comparison separately. In the network diagram, each node represents an intervention, and the edges represent head-to-head comparisons between a pair of interventions. The size of a node reflects the sample size for the intervention, and the thickness of an edge reflects the number of trials that included the comparison.

\section{Statistical analysis}

Pairwise meta-analyses

For airway complications, we will calculate the average OR and the $95 \%$ CI with the random effects using a mixedeffects logistic regression model. ${ }^{22}$ We will not assess the statistical heterogeneity within each pairwise comparison using the $\mathrm{I}^{2}$ because it has no useful interpretation. ${ }^{22-24}$

\section{Network meta-analysis}

The NMA will be performed in a Bayesian hierarchical framework using Markov Chain Monte Carlo method in WinBUGS V.1.4.3 (MRC Biostatistics Unit, Cambridge University, UK) ${ }^{25}$ If the network contains any loops connecting three or more interventions, we will use the node-splitting method to examine inconsistency between direct and indirect evidence for each loop. ${ }^{26}{ }^{27}$ To rank the treatments according to each outcome accounting for the uncertainty in the treatment effects, we will use the surface under the cumulative ranking curve. ${ }^{28}$ The absolute rank of the treatment per outcome is presented using 'rankograms' that visually show the distribution of ranking probabilities. ${ }^{28}$ All the result figures will be generated using STATA (V.13.0) software.

\section{Subgroup analysis}

If the necessary data are available, subgroup analyses will be done for both pairwise meta-analyses and NMAs according to different types of participants by gender, country and device size of cuff.

\section{Assessment of publication bias}

Begg's and Egger's funnel plot methods will be performed to help distinguish asymmetry due to publication bias when applicable. ${ }^{29} 30$

\section{Quality of evidence}

We will assess the quality of the evidence using the Grading of Recommendations Assessment, Development and Evaluation (GRADE) approach as outlined in the GRADE handbook in order to assess the quality of the body of evidence. The GRADE approach uses five considerations (study limitations, consistency of effect, imprecision, indirectness and publication bias) to assess the quality of the body of evidence for each outcome. The overall quality is classified into four levels: high level, moderate level, low level and very low level. ${ }^{31}$

\section{PATIENT AND PUBLIC INVOLVEMENT}

Patients and the public were not directly involved in the design or planning of the study.

\section{ETHICS AND DISSEMINATION}

This study will summarise and provide evidence of airway complications in the subtypes of LMA and i-gel in child 
patients under general anaesthesia. The results will be submitted to a peer-reviewed journal for publication. We hope the results of this NMA will help clinicians and patients to select an optimal laryngeal mask.

\section{Author affiliations}

${ }^{1}$ The First Clinical Medical College, Lanzhou University, Lanzhou, Gansu, China ${ }^{2}$ Department of Anesthesiology, Lanzhou University Second Hospital, Lanzhou, Gansu, China

${ }^{3}$ Evidence Based Meidicine Center, School of Basic Medical Sciences, Lanzhou University, Lanzhou, Gansu, China

${ }^{4}$ Department of Pediatrics Gastroenterology, Lanzhou University Second Hospital, Lanzhou, Gansu, China

${ }^{5}$ The Second Clinical Medical College, Lanzhou University, Lanzhou, Gansu, China ${ }^{6}$ Key Laboratory of Evidence Based Medicine and Knowledge Translation of Gansu Province, Lanzhou, Gansu, China

Contributors $\mathrm{JL}$ and $\mathrm{KY}$ planned and designed the research. $\mathrm{JL}, \mathrm{XX}, \mathrm{ML}, \mathrm{RC}$ and $\mathrm{KY}$ tested the feasibility of the study. JL and KY provided methodological advice, polished and revised the manuscript. JL, XX and KY wrote the manuscript. All authors approved the final version of the manuscript.

Funding The authors have not declared a specific grant for this research from any funding agency in the public, commercial or not-for-profit sectors.

Competing interests None declared.

Patient consent for publication Not required.

Ethics approval Ethics approval and patient consent are not required as this study is a network meta-analysis based on published trials.

Provenance and peer review Not commissioned; externally peer reviewed.

Open access This is an open access article distributed in accordance with the Creative Commons Attribution Non Commercial (CC BY-NC 4.0) license, which permits others to distribute, remix, adapt, build upon this work non-commercially, and license their derivative works on different terms, provided the original work is properly cited, appropriate credit is given, any changes made indicated, and the use is non-commercial. See: http://creativecommons.org/licenses/by-nc/4.0/.

\section{REFERENCES}

1 Brain Al. The laryngeal mask--a new concept in airway management Br J Anaesth 1983:55:801-5.

2 Brimacombe J. The advantages of the LMA over the tracheal tube or facemask: a meta-analysis. Can J Anaesth 1995;42:1017-23.

3 Kattwinkel J, Perlman JM, Aziz K, et al. Neonatal resuscitation: 2010 American heart association guidelines for cardiopulmonary resuscitation and emergency cardiovascular care. Pediatrics 2010;126:e1400-13.

4 Trevisanuto D, Verghese C, Doglioni N, et al. Laryngeal mask airway for the interhospital transport of neonates. Pediatrics 2005;115:e109-11.

5 Galderisi A, De Bernardo G, Lorenzon E, et al. i-gel: a new supraglottic device for effective resuscitation of a very low birthweight infant with Cornelia de Lange syndrome. BMJ Case Rep 2015;2015:bcr2014209124

6 Trevisanuto D, Parotto M, Doglioni N, et al. The Supreme laryngeal mask Airway ${ }^{\mathrm{TM}}$ (LMA): a new neonatal supraglottic device: comparison with classic and ProSeal LMA in a manikin. Resuscitation 2012;83:97-100.

7 Choi GJ, Kang H, Baek CW, et al. A systematic review and meta-analysis of the $\mathrm{i}-\mathrm{gel}{ }^{\circledR}$ vs laryngeal mask airway in children. Anaesthesia 2014;69:1258-65.
8 de Montblanc J, Ruscio L, Mazoit JX, et al. A systematic review and meta-analysis of the i-gel(®) vs laryngeal mask airway in adults. Anaesthesia 2014;69:1151-62.

9 Park SK, Choi GJ, Choi YS, et al. Comparison of the i-gel and the laryngeal mask airway proseal during general anesthesia: a systematic review and meta-analysis. PLoS One 2015;10:e0119469.

10 Shin HW, Yoo HN, Bae GE, et al. Comparison of oropharyngeal leak pressure and clinical performance of LMA ProSeal ${ }^{\mathrm{TM}}$ and i-gel $\circledR$ in adults: meta-analysis and systematic review. J Int Med Res 2016;44:405-18.

11 Gao Y, Ge L, Ma X, et al. Improvement needed in the network geometry and inconsistency of Cochrane network meta-analyses: a cross-sectional survey. J Clin Epidemiol 2019;113:214-27.

$12 \mathrm{Li}$ L, Tian J, Tian H, et al. Network meta-analyses could be improved by searching more sources and by involving a librarian. J Clin Epidemiol 2014;67:1001-7.

$13 \mathrm{Ge}$ L, Tian J-H, Li Y-N, et al. Association between prospective registration and overall reporting and methodological quality of systematic reviews: a meta-epidemiological study. J Clin Epidemiol 2018;93:45-55.

14 Tian J, Zhang J, Ge L, et al. The methodological and reporting quality of systematic reviews from China and the USA are similar. J Clin Epidemiol 2017:85:50-8.

15 Gao Y, Li J, Ma X, et al. The value of four imaging modalities in diagnosing lymph node involvement in rectal cancer: an overview and adjusted indirect comparison. Clin Exp Med 2019;19:225-34.

16 Gao Y, Cai Y, Yang K, et al. Methodological and reporting quality in non-Cochrane systematic review updates could be improved: a comparative study. J Clin Epidemiol 2019;119:36-46.

17 Bafeta A, Trinquart L, Seror R, et al. Reporting of results from network meta-analyses: methodological systematic review. BMJ 2014;348:g1741.

18 Bafeta A, Trinquart L, Seror R, et al. Analysis of the systematic reviews process in reports of network meta-analyses: methodological systematic review. BMJ 2013;347:f3675.

19 Hutton B, Salanti G, Caldwell DM, et al. The PRISMA extension statement for reporting of systematic reviews incorporating network meta-analyses of health care interventions: checklist and explanations. Ann Intern Med 2015;162:777-84.

20 Yan $\mathrm{P}$, Yao L, Li H, et al. The methodological quality of robotic surgical meta-analyses needed to be improved: a cross-sectional study. J Clin Epidemiol 2019;109:20-9.

21 Higgins JPT, Altman DG, Gøtzsche PC, et al. The Cochrane collaboration's tool for assessing risk of bias in randomised trials. BMJ 2011;343:d5928.

22 Chang B-H, Hoaglin DC. Meta-analysis of odds ratios: current good practices. Med Care 2017;55:328-35.

23 Hoaglin DC. Misunderstandings about $Q$ and 'Cochran's $Q$ test' in meta-analysis. Stat Med 2016;35:485-95.

24 Hoaglin DC. Practical challenges of as a measure of heterogeneity. Res Syn Meth 2017;8.

25 Lunn DJ, Thomas A, Best N, et al. WinBUGS-A Bayesian modeling framework: concepts, structure, and extensibility. Stat Comput 2000;10:325-37.

26 Dias S, Welton NJ, Caldwell DM, et al. Checking consistency in mixed treatment comparison meta-analysis. Stat Med 2010;29:932-44.

27 Dias S, Welton NJ, Sutton AJ, et al. Evidence synthesis for decision making 4: inconsistency in networks of evidence based on randomized controlled trials. Med Decis Making 2013;33:641-56.

28 Salanti G, Ades AE, loannidis JPA. Graphical methods and numerica summaries for presenting results from multiple-treatment metaanalysis: an overview and tutorial. J Clin Epidemiol 2011;64:163-71.

29 Begg CB, Mazumdar M. Operating characteristics of a RANK correlation test for publication bias. Biometrics 1994;50:1088.

30 Egger M, Davey Smith G, Schneider M, et al. Bias in meta-analysis detected by a simple, graphical test. BMJ 1997;315:629-34.

31 Puhan MA, Schünemann HJ, Murad MH, et al. A grade Working group approach for rating the quality of treatment effect estimates from network meta-analysis. BMJ 2014;349:g5630. 